\title{
A comparison of coincident GRACE and ICESat data over Antarctica
}

\author{
Brian Gunter - T. Urban - R. Riva • M. Helsen • \\ R. Harpold · S. Poole $\cdot$ P. Nagel · B. Schutz • \\ B. Tapley
}

Received: 21 November 2008 / Accepted: 19 May 2009 / Published online: 24 June 2009

(C) The Author(s) 2009. This article is published with open access at Springerlink.com

\begin{abstract}
In this study, we present a comparison of coincident GRACE and ICESat data over Antarctica. The analysis focused on the secular changes over a 4-year period spanning from 2003 to 2007, using the recently reprocessed and publicly available data sets for both missions. The results show that the two independent data sets possess strong spatial correlations, but that there are several factors that can significantly impact the total derived ice mass variability from both missions. For GRACE, the primary source of uncertainty comes from the modelling of glacial isostatic adjustment, along with the estimates of $C_{2,0}$ and the degree one terms. For ICESat, it is shown that assumptions about firn density, rate biases, and the sampling interval of the various laser campaigns can have large effects on the results. Despite these uncertainties, the similarities that do exist indicate a strong potential for the future refinement of both GIA and mass balance estimates of Antarctica.
\end{abstract}

Keywords GRACE - ICESat - Antarctica $\cdot$ Ice mass change $\cdot$ Glacial isostatic adjustment (GIA)

\footnotetext{
B. Gunter $(\varangle) \cdot$ R. Riva

Delft Institute of Earth Observation and Space Systems (DEOS),

Delft University of Technology, Kluyverweg 1, 2629 HS Delft,

The Netherlands

e-mail: b.c.gunter@tudelft.nl

T. Urban · R. Harpold · S. Poole $\cdot$ P. Nagel $\cdot$ B. Schutz $\cdot$ B. Tapley Center for Space Research, The University of Texas at Austin, Austin, TX, USA

M. Helsen

Institute for Marine and Atmospheric Research Utrecht (IMAU), Utrecht University, Utrecht, The Netherlands
}

\section{Introduction}

The Gravity Recovery and Climate Experiment (GRACE) and the Ice, Cloud and land Elevation Satellite (ICESat) missions have been collecting coincident measurements since the launch of ICESat in 2003. Both satellites are particularly valuable for polar studies, since their orbit inclinations ensure a high concentration of observations at the high latitudes. GRACE measures monthly mass variability with precision at the level of mm of geoid height, and at spatial scales of hundreds of kilometers (Tapley et al. 2004). ICESat's fourteen campaigns to date can observe surface heights with single-shot centimeter-level precision (sub-decimeter-level accuracy) (Schutz et al. 2005). One of the obvious questions that follows from the comparison of these two data types is whether the mass changes observed by GRACE can be correlated to the mass changes that can be derived from ICESat. If so, then these two data sets could be used as an independent validation of each other, or more importantly, they have the potential to improve the determination of ice mass estimates in regions such as Antarctica, where the present uncertainties can be quite large.

These concepts are not new (Wahr et al. 2000; Wu et al. 2002), and served as one of the many motivating factors behind the launch of both missions; however, two recent milestones have made these ideas more achievable. The first involves the fact that the time series of coincident data for both missions now extends beyond 4 years, allowing multiyear trends to be more precisely determined. The other involves the recent reprocessing of both of the publically available GRACE and ICESat data sets, which contain noticeable improvements over previous releases.

The objectives of this paper are to highlight these improvements and to evaluate the similarities and differences of the results obtained from the two data sets, in particular over 
Antarctica. The results presented will focus on multi-year secular trends observed in elevation and mass variability, and will present a limited comparison of GRACE and ICESat mass change estimates using mission data. The overall goal of improving the mass balance estimates over Antarctica is the subject of current research efforts and is beyond the scope of this paper; however, the results obtained with this initial comparison demonstrate the potential of this work toward this end.

\section{GRACE processing}

The GRACE analysis made use of the latest release of data (RL04) produced by the Center for Space Research (CSR), and which consist of a series of monthly spherical harmonic solutions that extend to degree and order $60(60 \times 60)$. This release represents a significant improvement over the previous CSR data release (RL01), as many advancements were made to both the background models and processing strategies.

For all GRACE solutions used in this study, the $C_{2,0}$ coefficients were replaced by those derived from satellite laser ranging (SLR), as taken from GRACE Technical Note \#5 (Cheng and Ries 2008). While the substituted $C_{2,0}$ coefficients are believed to be an improvement over the original estimated values, it is important to note that this particular coefficient has a substantial impact on the mass change estimates derived from GRACE over Antarctica (Gunter et al. 2008). This is because the coefficient, which represents the Earth's oblateness, manifests itself as a bias over Antarctica due to the continent's geographical location. Antarctica's large surface area means that even a small error in its estimate (e.g., on the order of $1 \times 10^{-12} /$ year) could translate into errors in the resulting mass change trend estimates that are on the order of tens of gigatons per year (Gt/year).

As part of the RL04 standard processing procedures (Bettadpur 2007), secular rates (also derived from SLR) are removed from the $C_{2,0}, C_{3,0}, C_{4,0}, C_{2,1}$ and $S_{2,1}$ harmonics, which are predominantly caused by the effects of glacial isostatic adjustment (GIA) (Cheng and Tapley 2004). As will be discussed shortly, a GIA model is removed from the GRACE solutions to isolate the ice mass change. As a result, the secular rates mentioned above are added back to their respective coefficients, before subtracting off the GIA model.

In addition to the modified $C_{2,0}$ coefficient, a number of studies have shown that ignoring the influence of the degree one terms can significantly affect estimates of ice mass variability (Davis et al. 2004; Chen et al. 2005; Wu et al. 2006). GRACE is not able to estimate these degree one harmonics directly; however, degree one terms were added to the GRACE fields with values derived from ocean and other GRACE pre-processing models, as outlined by Swenson et al. (2008).
To reduce the effects of noise in the GRACE data, several conditioning techniques were evaluated for the resulting solutions, including a scaled Kaula regularization as well as a "de-striping" filtering similar to that outlined by Swenson and Wahr (2006). For Antarctica, most techniques produced similar results after applying an appropriate level of Gaussian smoothing; however, in our opinion, the de-striped fields appeared to contain slight improvements in resolution over the other methods and were therefore chosen for the comparisons with the ICESat results. The particular destriping approach used for this study made use of a 3rd degree polynomial (Savitsky-Golay) over a 7-point window to remove the correlations, and orders below 8 were left unchanged.

\section{ICESat processing}

The analysis for this study made use of ICESat Release 428 (RL428) data, a series of fully calibrated, publicly available elevation data which now exists for fourteen laser altimeter campaigns collected since the mission was launched in 2003. This data product release corresponds to a radial orbit determination accuracy of $2 \mathrm{~cm}$ and surface laser spot location knowledge with $<5 \mathrm{~m}$ horizontal accuracy. Observed singleshot elevation accuracy is less than $10 \mathrm{~cm}$ with a precision under best conditions of 2-3 cm (Magruder et al. 2007).

ICESat elevation data from eleven of the fully calibrated campaigns were used for this study, spanning from the 2003 spring campaign (1a) to the 2007 spring campaign (3h) for a total span of 4 years. Note that while twelve campaigns were flown during this time span, data from the $2 \mathrm{c}$ campaign was not available at the initial time of this study. Elevation corrections available with RL428, such as saturation, were applied to the data. In addition, the data were edited when the spacecraft pointing angle was greater than $0.5^{\circ}$ off-nadir (such as when targeting a specific area of interest or during a calibration maneuver), and crossover differences greater than $2 \mathrm{~m}$ were excluded. The $2 \mathrm{~m}$ cutoff was sufficient to remove outliers early in the mission (e.g, Shuman et al. 2006); however this criterion could be revised for the longer time series and is a topic of future investigations.

ICESat elevation profiles were analyzed to find each track intersection (crossover). Over Antarctica, the ICESat laser is actively pointed toward a reference groundtrack, but variations in pointing control scatter the actual footprints about the reference with a $1-\sigma$ variation of $100 \mathrm{~m}$ (Webb et al. 2007). Therefore, comparison of two tracks from each pair of campaigns (1a vs. $2 \mathrm{a}, 1 \mathrm{a}$ vs. $2 \mathrm{~b}, \ldots, 3 \mathrm{~g}$ vs. $3 \mathrm{~h}$ ) yields a theoretical maximum of 55 distinct inter-campaign crossovers from the eleven campaigns examined, falling within a $\sim(200 \mathrm{~m})^{2}$ area. Intra-campaign crossovers (spanning $<33$ days) were not included. The precise crossover elevations and locations for this study were determined via cubic-spline interpolation 
of data within $0.25 \mathrm{~s}$ (up to 10 valid points) of the crossover time, resulting in more than 4 million total crossovers. Crossover height differences were computed as "later campaign minus earlier", i.e. yielding negative height changes where elevation loss has occurred. These crossover height differences were converted to height rates $(\mathrm{d} h / \mathrm{d} t)$ using the interpolated crossover times for each track/campaign.

Crossovers lend themselves to determining accurate height rates as opposed to direct height differences (repeat track analysis) as they inherently eliminate cross-track slope ambiguity if the crossing tracks are not nearly parallel. Averaging millions of discrete crossovers is useful because it reduces the impact of cloud and other data-gap-causing effects and makes use of all the data available. This methodology provides a consistent indication of the long-term trends in the elevation change, assuming that the overall trend dominates inter-annual variations and that the crossover sampling is sufficient to characterize the elevation changes over the time span and on the spatial scales examined.

When processing the ICESat data, it is important to account for potential elevation biases between campaigns. For this study, inter-campaign bias corrections were derived over the global oceans by comparison to a mean sea surface topography model based on TOPEX/Poseidon (Urban and Schutz 2005). ICESat data were limited to within the $\pm 66^{\circ}$ latitude bounds of TOPEX/Poseidon and Jason-1. The bias calculations indicate that ICESat elevations are below the true surface (the mean sea surface) and apparently that the bias decreases as time progresses. The trend through these biases was estimated to be $2.3 \pm 0.9 \mathrm{~cm} /$ year for the February 2003 to February 2007 time frame (see Fig. 1). This trend was adjusted for actual sea level rise $(0.3 \mathrm{~cm} /$ year; Leuliette et al. 2004), to determine a final bias correction of $2 \mathrm{~cm} /$ year. A similar bias rate was obtained using an alternate approach in which areas of little to no precipitation in East

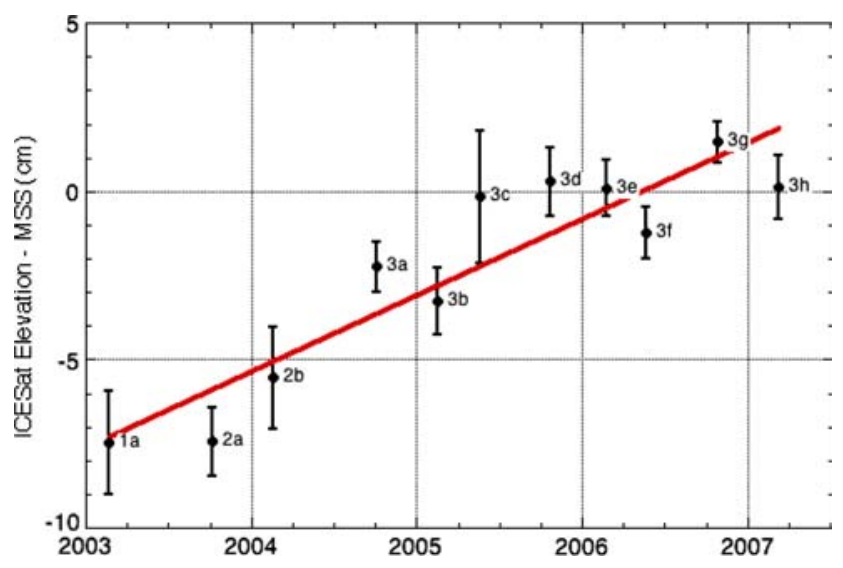

Fig. 1 Trend derived from the ICESat campaign biases computed from comparisons to a mean sea surface model. The computed trend is $2.3 \mathrm{~cm} /$ year, or $2.0 \mathrm{~cm} /$ year after adjusting for an assumed rate of $0.3 \mathrm{~mm} /$ year of actual sea level rise
Antarctica were used as the validation zone (Gunter et al. 2008). This suggests that the biases are global in nature and that this trend correction can be applied to this analysis of Antarctica. The accurate determination of these biases is particularly important for the mass change estimates from ICE$\mathrm{Sat}$, as every $\mathrm{mm}$ in bias corresponds to a near $5 \mathrm{Gt} /$ year change in the computed mass trend (using our preferred density model).

The $94^{\circ}$ inclination of ICESat means that there is a $4^{\circ}$ gap at the pole where no measurements are available. This area is about $6 \%$ of the total area of Antarctica. The mass change estimates from ICESat exclude this area, in essence setting the elevation change in this polar gap equal to zero (the impact of this polar gap on the comparison with GRACE data will be addressed later). Finally, the total annual volume change was computed from the derived height rates using a $0.2^{\circ}$ grid surfacing with no additional spatial smoothing applied.

\section{Derived ice mass changes}

Both the GRACE and ICESat data sets can be converted to ice mass changes using an appropriate conversion method. For the GRACE data, the ice mass estimates can be obtained by converting the spherical harmonic coefficients into equivalent water height (Wahr et al. 1998).

The de-striped GRACE fields were all smoothed with a $400 \mathrm{~km}$ Gaussian filter during the conversion to equivalent water height. While this technique is effective at removing random noise in the signal, it also has the effect of attenuating signal at the coastal boundaries, due to the blending with the near-zero signal over the oceans (i.e., leakage). In order to recover the signal that leaks into the ocean as part of the smoothing process, the area of integration for the GRACE mass balance estimates was extended into the ocean by an optimally determined value (obtained through simulation), which is approximately $350 \mathrm{~km}$. This approach assumes that the mass variability over the oceans is negligibly small. It should be noted that this approach is feasible only for regions such as Antarctica, which are surrounded by areas of nearzero mass variability (i.e., ocean). In general, this technique is not recommended for other regions, such as continental river basins, due to the potential leakage from external areas. For these cases, a more optimized filter (Klees et al. 2008) is usually the best option.

To derive mass changes from the ICESat-derived elevation changes, the density of the firn layer needs to be taken into account. If it is assumed that the vertical ice velocity (compaction and ice flow) is in balance with the long-term average accumulation rate, then the elevation changes can be attributed to accumulation anomalies over the observed period. Thus, associated mass changes can be calculated from the observed elevation changes by using the mean density of the 
firn that accumulated during this period. Some exceptions to this assumption will be discussed later for certain regions in which the vertical ice velocities are likely not to be in balance with the long-term accumulation rate (such as the Amundsen Sea sector).

The densities used for this study were the product of a parametrization of surface snow density (Kaspers et al. 2004) using mean annual values of accumulation, surface temperature and $10 \mathrm{~m}$ wind speed from the RACMO2/ANT (van de Berg et al. 2006) climate model, as shown in Fig. 2. It is important to note that accumulation rate changes occur on a variety of time-scales. Interannual and decadal accumulation variability can be large, and this can have significant effects on firn depth variability. For this study, the goal was simply to use realistic density values as a first approximation. An updated firn density profile (with velocities) covering the full GRACE/ICESat observation period is the subject of future work.

\section{Glacial isostatic adjustment}

For the results to be shown in the next section, the effects of glacial isostatic adjustment (GIA) were accounted for in each

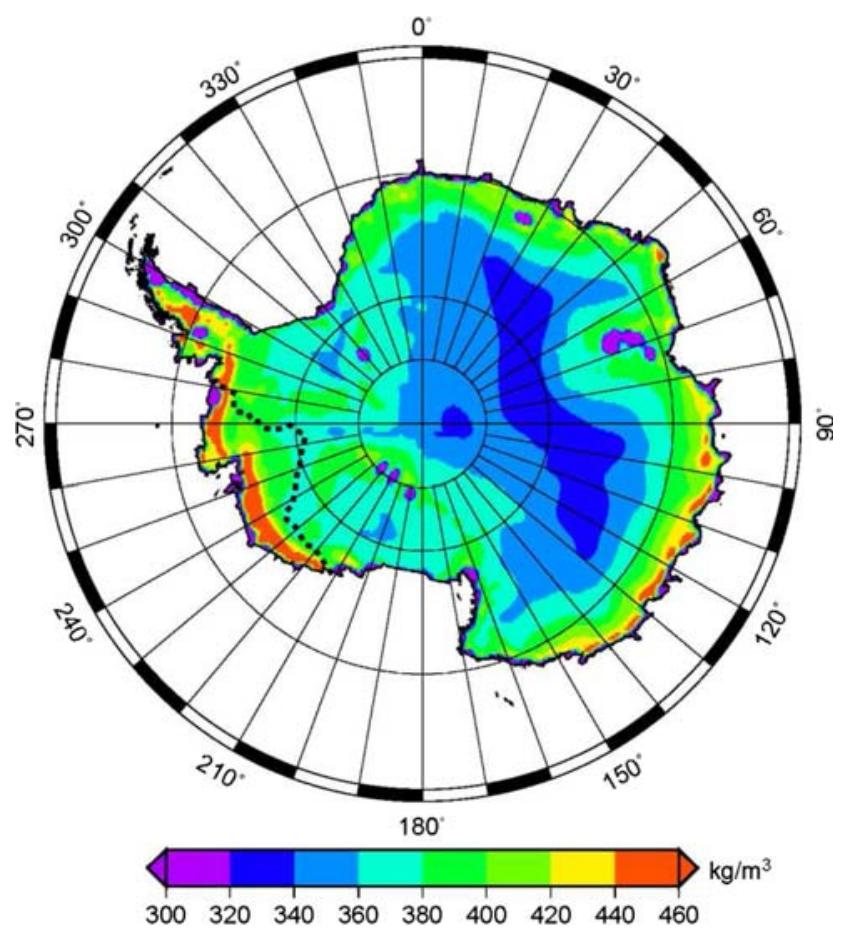

Fig. 2 Densities in $\mathrm{kg} / \mathrm{m}^{3}$ used to convert the ICESat derived height changes into ice mass change estimates. The densities were computed using a semi-empirical approach, with input data from the RACMO2/ANT climate model. The dotted line represents the outline of the Amundsen Sea sector, whose modeled densities are likely underestimated given current melting trends in that area
GRACE and ICESat solution using an incompressible selfgravitating normal modes model (Vermeersen and Sabadini 1997) with combinations of different Earth and ice models. Results are obtained after solving the full sea-level equation (Farrell and Clark 1976) and accounting for the influence of contemporaneous perturbations to the rotation vector of the planet (Milne and Mitrovica 1998). For comparison, two recent and widely used ice models were selected, one developed by Ivins and James (2005) (IJ05) and the other by Peltier (2004) (ICE-5G). For each ice model, the contribution of GIA was computed using a radially stratified Earth model with an elastic lithosphere and a viscosity jump between upper and lower mantle.

There are considerable differences between IJ05 and ICE$5 \mathrm{G}$ in terms of total ice load and melt history. In addition, the IJ05 model only describes ice loads over Antarctica, and does not provide information about the rest of the globe. The effect of ice loads on the Northern Hemisphere represents a significant portion of the total GIA signal observed in Antarctica. As a result, the contribution of the Northern Hemisphere was modeled separately using ICE-5G, with Earth model parameters fixed to those of VM2 (Peltier 2004), resulting in mass changes of roughly 27 gigatons per year (Gt/year). In this way, the effect of different ice and Earth models has been limited to the GIA signal caused by Antarctic ice history. Note that future references to the IJ05 model in this paper will imply that this contribution from the Northern Hemisphere has been included.

In addition to the load history, the choice of Earth model parameters is another factor that can have a significant impact on the degree of estimated GIA from these models (Barletta et al. 2008). To explore the impact of these choices, a range of mantle viscosities and lithospheric thicknesses were tested (again, only for loads over Antarctica). Upper mantle variations ranged from $1-10 \times 10^{20} \mathrm{~Pa} \mathrm{~s}$, lower mantle variations from $1-100 \times 10^{21} \mathrm{~Pa} \mathrm{~s}$, and lithospheric thicknesses from $65-120 \mathrm{~km}$. The total uncertainty introduced by these parameters, expressed in terms of Gt/year, is summarized in Fig. 3 for both the ICE-5G and IJ05 models. As the figure indicates, the choice of model, along with the variation of the mantle viscosities and lithospheric thicknesses, can alter the size of the GIA signal by up to $150 \mathrm{Gt} / \mathrm{year}$ (205 max-55 min).

A robust treatment of the merits and differences of the various available GIA models is beyond the scope of this paper, so to restrict the possibilities, a specific set of Earth model parameters were chosen for both the IJ05 and ICE-5G models. For ICE-5G, we used a simplified version of the recommended VM2 Earth model parameters. A recommended Earth model is not provided with IJ05, so the decision was made to use a slightly thinner lithosphere $(100 \mathrm{~km})$ and higher viscosity for the lower mantle $\left(10^{22} \mathrm{~Pa} \mathrm{~s}\right)$, in agreement with other previously published results (e.g., Mitrovica and Forte 2004). In terms of mass change, the contribution of these two 


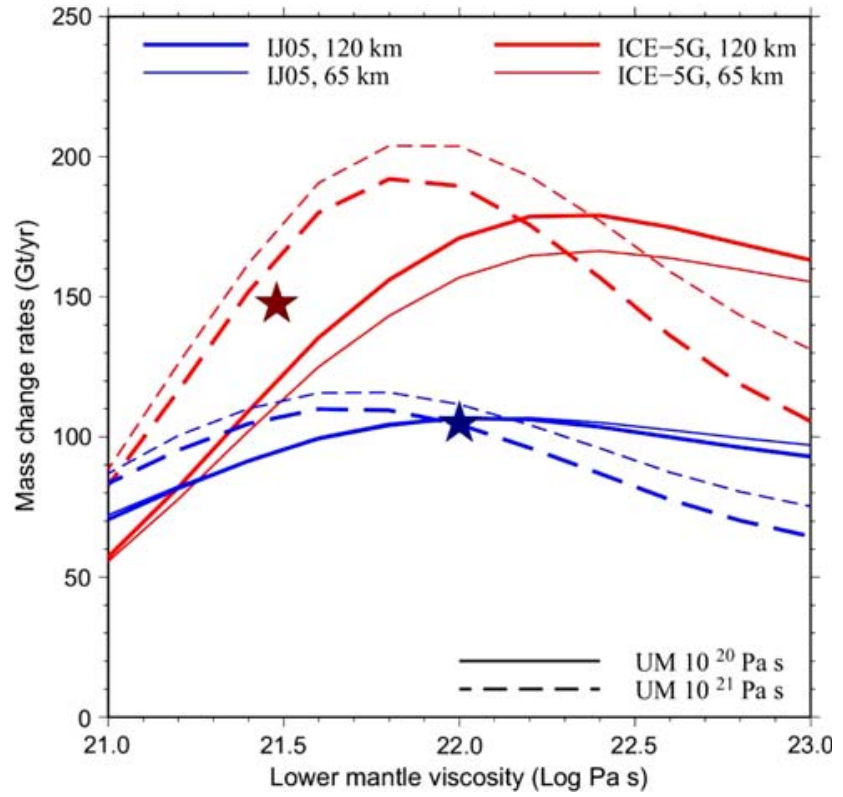

Fig. 3 The influence of the choice of ice model (ICE-5G, IJ05) and Earth model parameters (lithospheric thickness, upper and lower mantle viscosity) on the total contribution of the GIA signal, in terms of gigatons per year of equivalent water height. The stars indicate the authors' preferred parameters for both models, which for ICE-5G correspond to the standard VM2 parameters

models over the whole continent (including the ice shelves) is approximately $149 \mathrm{Gt} /$ year for ICE-5G and $107 \mathrm{Gt} /$ year for IJ05. These fixed parameter models are indicated by stars in Fig. 3.

For GRACE, this GIA signal can be subtracted directly from the harmonic coefficients before any spatial filtering is applied. For ICESat, the annual change in surface elevation due to GIA is first calculated, which can then be removed from the computed height rate changes for ICESat.

When computing the mass change estimates for both GRACE and ICESat, areas over the ice shelves were excluded using the grounding line described by Vaughan et al. (1999). This is done because, for GRACE, the isostatic reaction of the ocean on the ice shelves means that any observed mass change under the ice shelves would be due to GIA. Since the effects of GIA are removed with the aforementioned models, any remaining signal over the ice shelves is considered noise. As a result, the ice mass change estimates outlined in this paper only represent those of the grounded ice sheets.

\section{Results}

Figure 4 provides a side-by-side comparison of the GRACE and ICESat data sets. As already discussed, the estimates of GIA can vary considerably, so the figure shows the observations in their original form, before any GIA model has
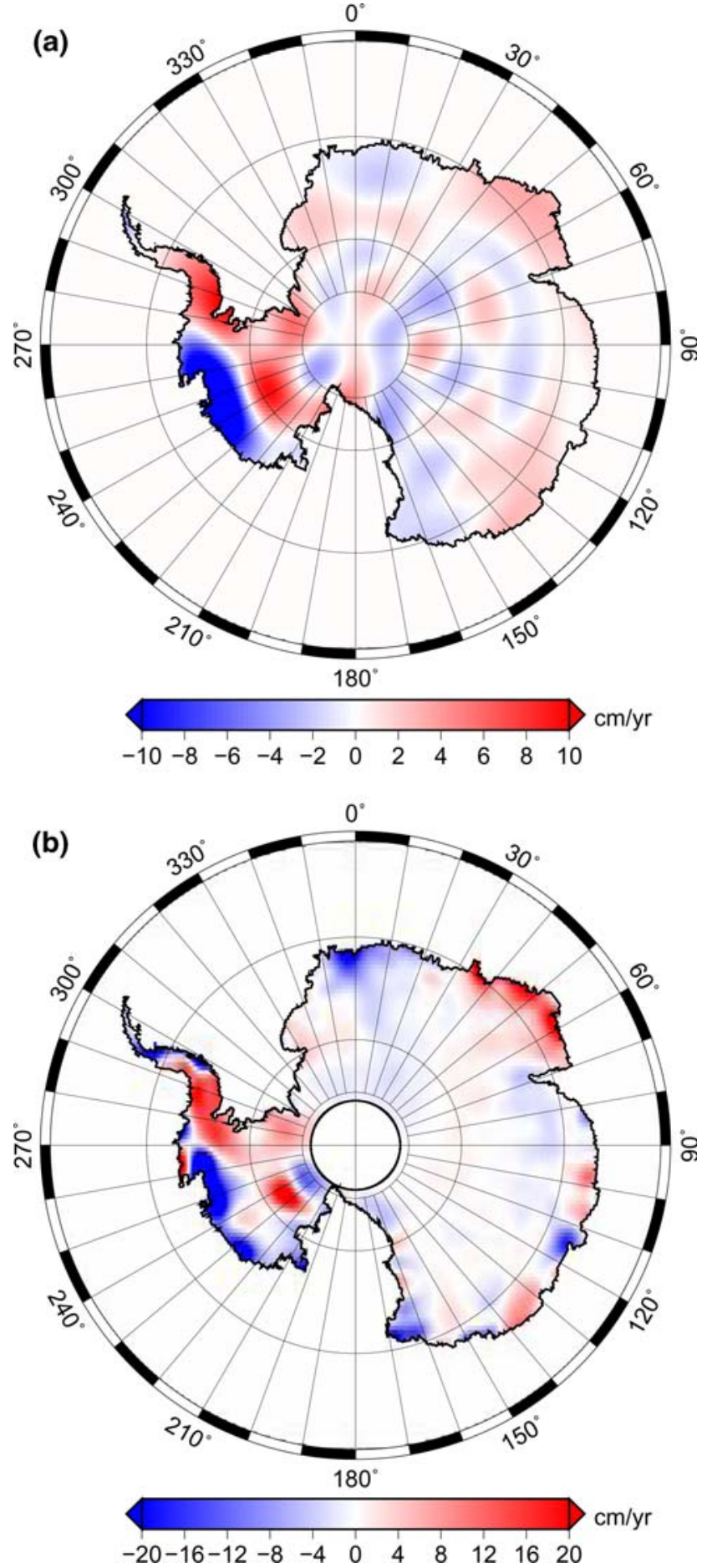

Fig. 4 A comparison of the GRACE and ICESat data sets over the February 2003 to February 2007 time span. a The mass changes derived from RL04 GRACE data in terms of equivalent water height, while $\mathbf{b}$ the averaged crossover height differences $(\mathrm{d} h / \mathrm{d} t)$ derived from RL428 ICESat data. Note that even though the maps are in different units (equivalent water height vs. surface height rate), high spatial correlations are clearly evident

been removed. Panel (a) shows the GRACE mass estimates, converted to $\mathrm{cm} /$ year of equivalent water height, created by fitting a simple linear trend through the (unsmoothed) time 
series of monthly GRACE solutions (i.e., February 2003 to February 2007). Panel (b) shows the ICESat height rates $(\mathrm{d} h / \mathrm{d} t)$ in $\mathrm{cm} /$ year derived from the eleven campaigns over same 4-year time span. Note that the ICESat map shown in Fig. 4 has been smoothed with a $100 \mathrm{~km}$ Gaussian filter to improve the visual comparison with GRACE; however, this smoothing was not used in the process of computing the mass change estimates for ICESat.

The most prominent feature of Fig. 4 is the high spatial correlation between the two plots, indicating that that the two missions are observing a majority of the ice mass variability with roughly the same location and relative intensity. Similar comparisons using earlier data releases did not show such a clear resemblance, highlighting the improvements gained by the recently reprocessed GRACE and ICESat data sets.

From the time series of both missions, the annual rate of ice mass change can be computed. For GRACE, 48 of the de-striped and smoothed monthly RL04 solutions available for the February 2003 to February 2007 interval were used to compute a series of mass change estimates. The results are shown in Table 1 in terms of Gt/year, and include values when removing the effects of GIA when using either ICE-5G and IJ05, as well as comparisons between trends computed with and without the inclusion of annual periodic terms. These results are consistent with values published by Velicogna and Wahr (2006) and Horwath and Dietrich (2009) for Antarctica, with any differences due primarily to the choice of GIA model, the newer data release, and the different time span evaluated; however, the estimates are in general lower than those produced by Rignot et al. (2008) (derived from InSAR and climate models), and larger than other GRACE derived results produced by Chen et al (2006) and Ramillien et al. (2006).

Table 1 Ice mass change trend estimates for GRACE and ICESat, in Gt/year

\begin{tabular}{|c|c|c|c|}
\hline \multirow[t]{2}{*}{ Mission } & \multicolumn{2}{|c|}{ GIA model } & \multirow[t]{2}{*}{ Description } \\
\hline & IJ05 & ICE-5G & \\
\hline GRACE & -64 & -91 & Trend only \\
\hline GRACE & -75 & -102 & Trend incl. ann. terms \\
\hline GRACE & -74 & -92 & $\begin{array}{l}\text { Trend incl. ann. terms, removing } \\
\text { GIA polar gap effects }\end{array}$ \\
\hline ICESat & -24 & -26 & Using standard surface densities \\
\hline ICESat & -56 & -59 & Using modified surface densities \\
\hline ICESat & -84 & -89 & $\begin{array}{l}\text { Using modified surface } \\
\text { densities,scaled by } 1.5 \text { to account } \\
\text { for possible sampling effects }\end{array}$ \\
\hline ICESat & -98 & -103 & $\begin{array}{l}\text { Using modified surface densities, } \\
\text { scaled by } 1.75 \text { to account for } \\
\text { possible sampling effects }\end{array}$ \\
\hline
\end{tabular}

When integrated over all of Antarctica, the averaged height rates derived from the ICESat campaigns generate a total uncorrected volume of $-50.2 \mathrm{~km}^{3}$. Using the density values from Fig. 2, and removing the bedrock uplift effects as predicted from the ICE-5G and IJ05 GIA models, translates into mass changes estimates of -26 and $-24 \mathrm{Gt} /$ year, respectively. These and other ICESat results are also presented in Table 1 to provide a comparison to the GRACE results. It is interesting to note that these initial ICESat estimates are close to previously published results $(-31 \mathrm{Gt} /$ year) derived from ERS-1 and ERS-2 altimetry (Zwally et al. 2005) for the period spanning from 1992 to 2001.

The uncertainties for the ICESat estimates are difficult to assess, since the spatial variations in the densities have a significant impact on the final mass change estimates, i.e., it is not sufficient to simply use a range of constant densities (i.e., $300-917 \mathrm{~kg} / \mathrm{m}^{3}$ ) for the determination of the uncertainties. As an example, regions such as the Amundsen Sea sector are known to have exhibited accelerated ice flow in recent years, which induce strong decreases of ice sheet elevation, i.e. vertical ice velocity (thinning) that exceeds the long-term accumulation rate (Thomas et al. 2004). For these regions, a density of $917 \mathrm{~kg} / \mathrm{m}^{3}$ might be more appropriate since it can be expected that a majority of the volume change can be attributed to the loss of ice. When the densities in the Amundsen Sea sector (denoted by the black dotted line in Fig. 2) are modified to reflect this higher density, the total mass change estimates for ICESat changes to -59 and $-56 \mathrm{Gt} /$ year when corrected for ICE-5G and IJ05, respectively (see also Table 1). This is a significant decrease, and there are likely other coastal basins experiencing accelerated ice flows to which this same concept could be applied. This example serves to highlight the importance that the determination of accurate regional densities has regarding these mass change estimates.

As mentioned earlier, there is a $4^{\circ}$ gap at the pole in the ICESat measurements due to the satellite's orbit inclination. There is not likely to be any sizeable surface mass variations in this polar gap; however, the contribution from GIA is not so inconsequential. In particular, the choice of GIA model used in the data processing has a noticeable influence on the comparison, since the models used in this study show different rates of uplift in this polar gap. When looking at the GRACE standard monthly solutions, uncorrected for GIA, the observed mass change trends over this polar gap are small at $2 \mathrm{Gt} /$ year or less (regardless of whether annual terms are included in the trend estimate). The IJ05 model predicts a mass change due to GIA over the polar gap to be slightly over $1 \mathrm{Gt} /$ year, which creates a total net change over this region of less than $1 \mathrm{Gt} /$ year. The ICE-5G model, however, predicts approximately $12 \mathrm{Gt} /$ year of GIA induced mass change over the polar gap, creating a net change of $10 \mathrm{Gt} /$ year (12 Gt/year from ICE-5G minus $2 \mathrm{Gt} /$ year from GRACE). 
If the ICE-5G model is believed to be correct, then this $10 \mathrm{Gt} /$ year represents a bias between the GRACE and ICESat estimates, since the GRACE estimates include the polar gap, while ICESat does not. For comparison, the potential correction of the polar gap effects due to the different GIA models is presented in Table 1 .

\section{Sampling issues}

Soon after ICESat was launched, the first of three on-board lasers failed. It was determined that the remaining two lasers would probably undergo the same accelerated degradation, and so to extend the lifetime of the mission to meet its longterm change-detection goals (Schutz et al. 2005), a modified mission scenario was implemented whereby the lasers would be activated for a 33-day sub-cycle of the 91-day repeat orbit, two or three times per year. While this enables long-term change monitoring, sparse temporal sampling means that certain seasonal signals are unobservable. While the averaging process used for the processing of the crossover points helps to mitigate the influence of seasonal effects, this undersampling could potentially alter the long-term mass change trends computed from the ICESat elevation change rates.

To explore the impact that this undersampling might have on the ICESat results, an experiment was devised that involved GRACE data. The basic principle behind the experiment was to compare the trends computed from the normal monthly GRACE solutions to special "tailored" GRACE solutions that were created to coincide with the exact days of the ICESat campaigns. Since the GRACE mission has nearly continuous observations during the entire 4-year time frame being examined (i.e., February 2003 to February 2007), the difference in computed trends between the standard monthly and tailored solutions should provide an indication of the potential undersampling error in the ICESat height rates (and subsequent mass change estimates).

The tailored GRACE solutions were processed from the level-1 data from the same days (approximately 33) as each of the twelve ICESat campaigns. The solutions were processed in the identical fashion as the standard CSR RL04 monthly fields, with the only exception being that the maximum degree and order estimated for the tailored solutions was extended to $120 \times 120$ instead of the standard $60 \times 60$ that is estimated for the publicly available CSR RL04 fields. To make the comparisons as equivalent as possible, only the $60 \times 60$ part of the tailored solutions were used in this analysis. Both sets of fields were destriped and smoothed with a $400 \mathrm{~km}$ Gaussian smoothing in the same manner as outlined earlier, and used the same extended integration area to compute the total mass change values. The results of the experiment are shown in Fig. 5, expressed in terms of gigatons (Gt) of total mass change from February 2003. Though not shown here, a comparison of the destriped and smoothed $60 \times 60$ and $120 \times 120$ tailored solutions showed that the trends computed from both time series were nearly identical, implying that the truncation to $60 \times 60$ does not have a noticeable impact on the results. The solutions for this experiment did not take into consideration GIA, since the goal was to see what the differences would be for the original, uncorrected signal.

The computation of the trends were done using two methods. The first only estimated a linear trend, while the second estimated a trend along with annual periodic terms. Biases were also estimated for each case, and have already been removed for the plots shown to illustrate relative mass changes. Figure 5a shows the standard monthly solutions along with the curve combining the estimated trend and annual terms. Figure 5b shows the same curves for the tailored GRACE solutions. Figure 5c shows only the annual curves for each case, illustrating that both data sets are at least able to estimate the proper phase of the dominant annual signal, even though the amplitudes are larger for the tailored solutions. Finally, Fig. 5d shows the computed trends for the two methods.

It should be noted that that the trends computed for these experiments made use of a slightly extended data set from those of the previous section. This is because the measurement period for the final ICESat campaign ( $3 \mathrm{~h}$ ) spanned from March 12 to April 14, 2007. This puts the midpoint of the corresponding tailored solution close to the beginning of April, 2007, which is beyond the end point of the usual standard monthly solution time series (February 2007). As such, the number of standard monthly solutions used in these comparisons was extended by two months to April, 2007, so that the time span of the GRACE data sets would encompass the entire ICESat time frame.

Several important observations can be made from the results of Fig. 5. The first is that, for both the standard monthly and tailored solutions, the computed trends vary only slightly when annual periodic terms are included in the estimation process. At least for the standard monthly solutions, this was somewhat expected, as the inclusion of the annual terms could be considered an over-parameterization, since the duration ( $\sim 4$ years) and the sampling interval (monthly) is sufficiently high to estimate a reliable trend (Blewitt and Lavallee 2006).

More important than the change observed when adding annual terms is the fact that a consistent difference can be seen in the estimated trend between the tailored and standard monthly solutions. For the trend-only case, the trend estimate from the tailored solutions is approximately $57 \%$ (18.5 Gt/year difference) that of the estimate from the standard monthly solutions. Similarly, when annual terms are included, the trend from the tailored solutions is $67 \%$ (13.5 Gt/year difference) that of the standard monthly solutions. This suggests that, regardless of how the trend is 

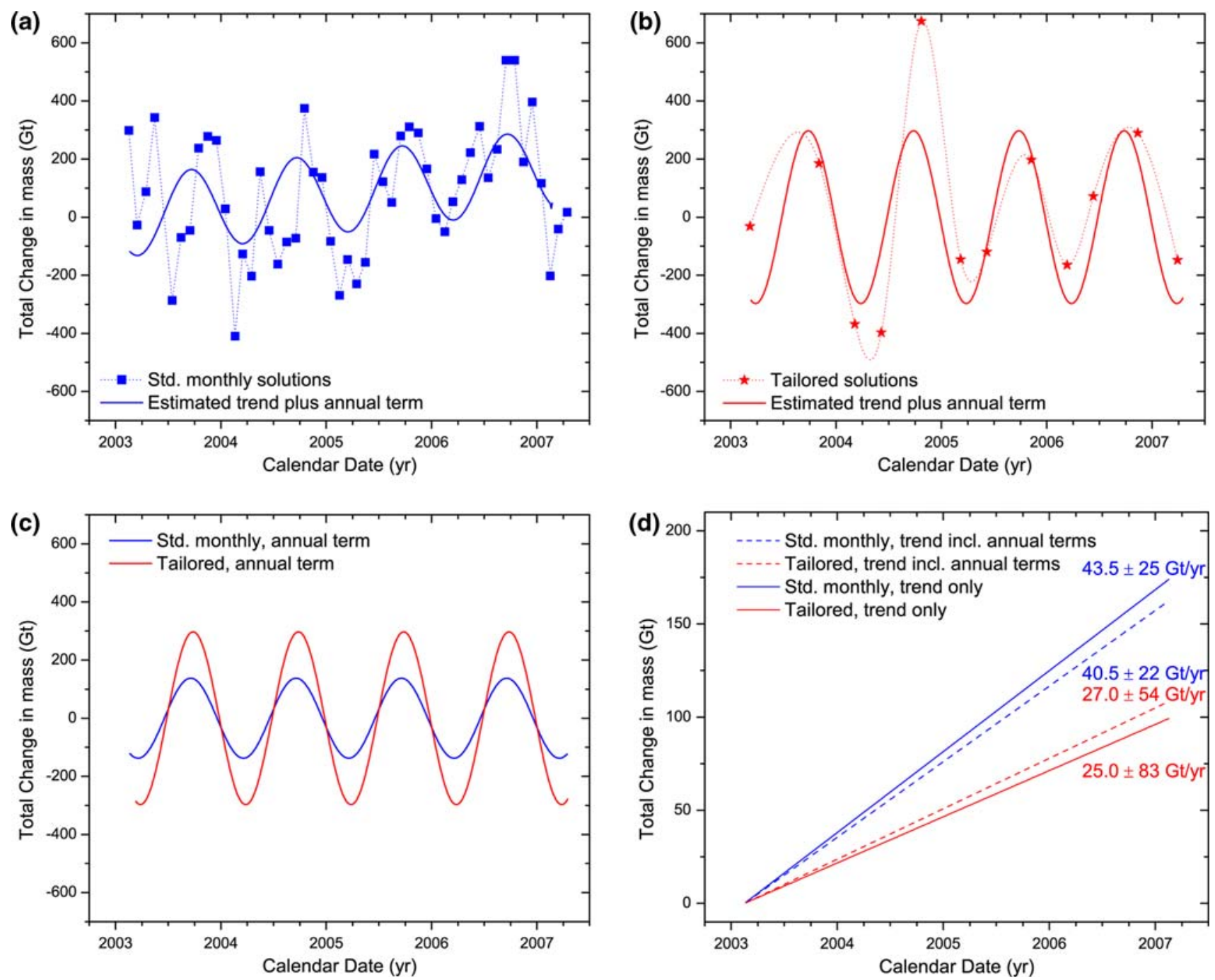

Fig. 5 Trends from both GRACE standard monthly solutions and special tailored solutions that made use of the same days as the various ICESat campaigns. For comparison, linear trends were estimated with and without annual periodic terms included. Bias terms were also estimated, and have already been removed from the data in the plots. Note

that the final trends for the tailored solutions are roughly two-thirds those of the standard monthly solutions. a GRACE monthly solutions, b GRACE tailored solutions, c comparison of the estimated annual curves, $\mathbf{d}$ comparison of the estimated linear trends

computed, the sampling interval of the tailored solutions over the specific 4-year interval examined is only able to predict a rate that is approximately two thirds that of the more densely sampled standard monthly solutions. If this is believed to be accurate, then it could be argued that a factor of approximately 1.5 to 1.75 should be applied to the ICESat-derived trend to more accurately represent the mass change estimates. If this is done using the modified densities (i.e., in which the Amundsen sea sector is given higher density), the total mass change estimate from ICESat would range from -84 to $-103 \mathrm{Gt} /$ year (see Table 1), depending on the GIA model removed, bringing the total mass change trend much more in line with the GRACE estimates.

Naturally, the analysis of the ICESat undersampling error using GRACE data has its limitations. First, the trends

computed from the tailored solutions are sensitive to the values of the limited number of data points available (twelve), as evidenced by the large standard deviations from the trend fits (e.g. $83 \mathrm{Gt} /$ year for the trend-only case, see Fig. 5 for the other cases). The large positive outlier in Fig. $5 \mathrm{~b}$ coincides with a near-repeat ground track period (October 2004) in the GRACE orbits, resulting in larger uncertainties for this solution. This error is GRACE specific, so in addition to having a noticeable influence on the estimated trend, the error itself would not represent those of ICESat, making the interpretation of the results more difficult. Additional experiments on the data sets described above show that, given a purely annual signal, the ICESat sampling interval is sufficiently dense enough to recover the signal accurately. This implies that it is primarily shorter term variations or other 
non-periodic signals that cause errors in the trend estimates. Experiments in which trends from the tailored solutions were computed with additional semi-annual terms confirm this notion, as the recovered amplitudes and trends were unrealistically large. Future studies will investigate whether these short term and non-periodic signals are dominated by genuine mass change or processing errors inherent to the GRACE data.

Despite these limitations, the experiments are valuable because they show that the sampling rate could indeed have a sizeable impact on the mass estimates from ICESat, although more investigations are needed before a reliable value of this undersampling error can be determined. If, ultimately, it turns out that the sampling rate is not the predominate cause of the lower mass estimates from ICESat, then this is also useful information. It would suggest that the discrepancy between the GRACE and ICESat estimates is then primarily due to errors in the densities or campaign rate bias, allowing future efforts to focus on improvements to these two specific items.

\section{Discussion}

The strong spatial correlations observed between the GRACE and ICESat results are encouraging, and demonstrate that the two missions are observing the same general features over Antarctica; however, the mass change estimates derived from the two missions can differ significantly given certain model choices and assumptions. The results reaffirm the notion that there are still many aspects of the input modeling that are not accurately known, but which can significantly impact the mass change estimates. For ICESat, the primary uncertainties involve the accurate modeling of the firn compaction and ice densities, as well as the accurate determination of the campaign biases and undersampling errors. For GRACE, the GIA model represents the largest degree of uncertainty, along with the accurate determination of the $C_{2,0}$ (which effectively represents a bias over Antarctica) and degree one coefficients. The choice of spatial filtering and the influence of temporal aliasing should also not be undervalued. The improvement of these items and others is an active research topic within the Earth science community, so the agreement between ICESat and GRACE (as well as other missions), is expected to improve in the near future.

Provided that certain advances in the models and processing techniques for both missions can be made, in particular with respect to the firn models, the combination of the GRACE and ICESat data sets should permit the separation of the mass change signal from that of the GIA signal. For example, if it is assumed that the secular changes observed by GRACE and ICESat are more accurate than the current GIA models for Antarctica, then it might be possible to constrain the location and magnitude of these secular changes to improve future GIA models. There have already been some suggestions on how this might be accomplished in the literature (Wahr et al. 2000; Wu et al. 2002), and future work will explore these and other methodologies.

Acknowledgments The authors would like to thank J. Wahr, $\mathrm{S}$. Nerem, and the anonymous referees for their many valuable comments and discussions. Parts of this study were funded by NASA grants NAS5-99005 and NAS5-97213.

Open Access This article is distributed under the terms of the Creative Commons Attribution Noncommercial License which permits any noncommercial use, distribution, and reproduction in any medium, provided the original author(s) and source are credited.

\section{References}

Barletta V, Sabadini R, Bordoni A (2008) Isolating the PGR signal in the GRACE data: impact on mass balance estimates in Antarctica and Greenland. Geophys J Int 172:18-30. doi:10.1111/j.1365-246X. 2007.03630.x

Bettadpur S (2007) CSR Level-2 Processing Standards Document for Product Release 04 GRACE 327-742, 3rd edn. Center for Space Research. http://podaac.jpl.nasa.gov/grace/documentation.html

Blewitt G, Lavallee D (2006) Effect of annual signals on geodetic velocity. J Geophys Res 107(B7). doi:10.1029/2001JB000570

Chen J, Rodell M, Wilson C, Famiglietti J (2005) Low degree spherical harmonic influences on Gravity Recovery and Climate Experiment (GRACE) water storage estimates. Geophys Res Lett 32(L14405). doi:10.1029/2005GL022964

Chen JL, Wilson CR, Blankenship DD, Tapley BD (2006) Antarctic mass rates from GRACE. Geophys Res Lett 33(L11502). doi:10. 1029/2006GL026369

Cheng M, Ries J (2008) Monthly estimates of C20 from 5 SLR satellites. Tech. rep., Center for Space Research. http://podaac.jpl.nasa. gov/grace/documentation.html

Cheng M, Tapley BD (2004) Variations in the earth's oblateness during the past 28 years. J Geophys Res 109(B9)

Davis J, Elsegui P, Mitrovica J, Tamisiea M (2004) Climate-driven deformation of the solid earth from GRACE and GPS. Geophys Res Lett 31(L24605). doi:10.1029/2004GL021435

Farrell W, Clark JT (1976) On postglacial sea level. Geophys J R Astron Soc 46:647-667

Gunter B, Riva R, Urban T, Schutz B, Harpold R, Helsen M, Nagel P (2008) Evaluation of GRACE and ICESat mass change estimates over Antarctica. In: Proceedings of the IAG international symposium on gravity, geoid and earth observation (GGEO), Chania, Greece

Horwath M, Dietrich R (2009) Signal and error in mass change inferences from GRACE: the case of Antarctica. Geophys J Int. doi:10. 1111/j.1365-246X.2009.04139.x

Ivins ER, James TS (2005) Antarctic glacial isostatic adjustment: a new assessment. Antarctic Sci 17(4):541-553

Kaspers KA, van de Wal R, van den Broeke MR, Schwander J, van Lipzig NPM, Brenninkmeijer CAM (2004) Model calculations of the age of firn air across the Antarctic continent. Atmos Chem Phys 4:1365-1380

Klees R, Revtova E, Gunter B, Ditmar P, Oudman E, Winsemius H, Savenije H (2008) Filter design for GRACE gravity models. Geophys J Int 175(2):417-432

Leuliette E, Nerem R, Mitchum G (2004) Calibration of TOPEX/Poseidon and Jason altimeter data to construct a continuous record of mean sea level change. Mar Geod 27:79-94 
Magruder L, Webb C, Urban T, Silverberg E, Schutz B (2007) ICESat altimetry data product verification at White Sands space harbor. IEEE Trans Geosci Rem Sen 45(1):147-155

Milne GA, Mitrovica JX (1998) Postglacial sea-level change on a rotating earth. Geophys J Int 133:1-9

Mitrovica J, Forte A (2004) A new inference of mantle viscosity based upon joint inversion of convection and glacial isostatic adjustment data. Earth Planet Sci Lett 225:177-189

Peltier W (2004) Global glacial isostasy and the surface of the ice-age earth: The ICE-5G (VM2) model and GRACE. Annu Rev Earth Planet Sci 32:111-149

Ramillien G, Lombard A, Cazenave A, Ivins E, Llubes M, Remy F, Biancale R (2006) Interannual variations of the mass balance of the Antarctica and Greenland ice sheets from GRACE. Glob Planet Change 53:198-208. doi:10.1016/j.gloplacha.2006.06.003

Rignot E, Bamber J, van den Broeke M, Davis C, Li Y, van de Berg W, van Meijgaard E (2008) Recent Antarctic ice mass loss from radar interferometry and regional climate modelling. Nat Geosci 1:106-110. doi:10.1038/ngeo102

Schutz B, Zwally HJ, Shuman C, Hancock D, DiMarzio R (2005) Overview of the ICESat mission. Geophys Res Lett 32. doi:10.1029/ 2005GL024009

Shuman CA, Zwally HJ, Schutz BE, Brenner AC, DiMarzio JP, Suchdeo VP, Fricker HA (2006) ICESat antarctic elevation data: Preliminary precision and accuracy assessment. Geophys Res Lett 33(L07501). doi:10.1029/2005GL025227

Swenson S, Wahr J (2006) Post-processing removal of correlated errors in GRACE data. J Geophys Res 33(L08402). doi:10.1029/ 2005GL025285

Swenson S, Chambers D, Wahr J (2008) Estimating geocenter variations from a combination of GRACE and ocean model output. J Geophys Res. doi:10.1029/2007JB005338

Tapley B, Bettadpur S, Watkins M, Reigber C (2004) The Gravity Recovery and Climate Experiment: mission overview and early results. Geophys Res Lett 31(L09607). doi:10.1029/2004GL019920

Thomas R, Rignot E, Casassa G, Kanagaratnam P, Acuna C, Akins T, Brecher H, Frederick E, Gogineni P, Krabill W, Manizade S, Ramamoorthy H, Rivera A, Russell R, Sonntag J, Swift R, Yungel J, Zwally J (2004) Accelerated sea-level rise from West Antarctica. Science 306:255. doi: 10.1126/science. 1099650
Urban T, Schutz BE (2005) ICESat sea level comparisons. Geophys Res Lett 32(L23S10). doi:10.1029/10.1029/2005GL024306

van de Berg WJ, van den Broeke MR, Reijmer $\mathrm{CH}$, van Meijgaard E (2006) Reassessment of the Antarctic surface mass balance using calibrated output of a regional atmospheric climate model. J Geophys Res 111(D11104). doi:10.1029/2005JD006495

Vaughan D, Bamber J, Giovinetto M, Russel J, Cooper A (1999) Reassessment of net surface mass balance in Antarctica. J Clim 12(4)

Velicogna I, Wahr J (2006) Measurements of time-variable gravity show mass loss in Antarctica. Science 311(1754). doi:10.1126/science. 1123785

Vermeersen L, Sabadini R (1997) A new class of stratified viscoelastic models by analytical techniques. Geophys J Int 129:531-570

Wahr J, Molenaar M, Bryan F (1998) Time variability of the Earth's gravity field: Hydrological and oceanic effects and their possible detection using GRACE. J Geophys Res 103(B12):30, 205-30, 230. doi:10.1029/98JB02844

Wahr J, Wingham D, Bentley C (2000) A method of combining ICESat and GRACE satellite data to constrain Antarctic mass balance. J Geophys Res 105(B7):16,279-16,294

Webb C, Stauch J, Harpold R, Lorhammer K, Schutz B, Born G (2007) ICESat off-nadir laser targeting: theory and practice. Adv Astronaut Sci 123:155-174

Wu X, Watkins MM, Ivins ER, Kwok R, Wang P, Wahr JM (2002) Toward global inverse solutions for current and past ice mass variations: Contribution of secular satellite gravity and topography change measurements. J Geophys Res 107(B11):2291. doi:10. 1029/2001JB000543

Wu X, Heflin M, Ivins E, Fukumori I (2006) Seasonal and interannual global surface mass variations from multisatellite geodetic data. J Geophys Res 111(B09401). doi:10.1029/2005JB004100

Zwally HJ, Giovinetto MB, Li J, Cornejo HG, Beckley MA, Brenner AC, Saba JL, Yi D (2005) Mass changes of the Greenland and Antarctic ice sheets and shelves and contributions to sea-level rise: 1992-2002. J Glaciol 51(175):509-527 